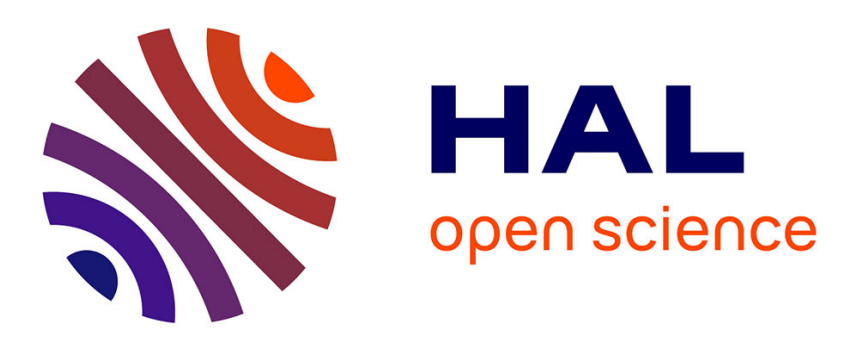

\title{
Formulate and evaluate population-specific complementary feeding recommendations using linear programming
}

\author{
Elaine Ferguson, Nicole N. Darmon, Umi Fahmida
}

\section{To cite this version:}

Elaine Ferguson, Nicole N. Darmon, Umi Fahmida. Formulate and evaluate population-specific complementary feeding recommendations using linear programming. Sight and Life Magazine, 2008, 3, pp.13-18. hal-02656323

\section{HAL Id: hal-02656323 \\ https://hal.inrae.fr/hal-02656323}

Submitted on 29 May 2020

HAL is a multi-disciplinary open access archive for the deposit and dissemination of scientific research documents, whether they are published or not. The documents may come from teaching and research institutions in France or abroad, or from public or private research centers.
L'archive ouverte pluridisciplinaire HAL, est destinée au dépôt et à la diffusion de documents scientifiques de niveau recherche, publiés ou non, émanant des établissements d'enseignement et de recherche français ou étrangers, des laboratoires publics ou privés. 


\title{
Formulate and Evaluate Population-specific Complementary Feeding Recommendations using Linear Programming
}

\author{
Elaine Ferguson ${ }^{1}$, Nicole Darmon ${ }^{2}$, Umi Fahmida $^{3}$ \\ ${ }^{1}$ London School of Hygiene and Tropical Medicine, London, UK; \\ 2INSERM (Human Nutrition and Lipids), INRA, and Université \\ Méditerranée Aix-Marseille, Faculté de Médecine, Marseille, France; \\ ${ }^{3}$ SEAMEO-TROPMED Regional Centre for Community Nutrition, \\ University of Indonesia, Jakarta, Indonesia
}

Correspondence: Elaine Ferguson, London School of Hygiene and Tropical Medicine, Keppel Street, London WC1E 7HT, UK Email: elaine.ferguson@1shtm.ac.uk

\section{Introduction}

Poor dietary quality is characteristic of complementary feeding diets consumed in disadvantaged environments; contributing to multiple micronutrient deficiencies and their associated adverse effects on infant health, growth and long term development. ${ }^{1}$ In response, international agencies have emphasized the need for country-specific approaches to improve complementary feeding diets, including evidencebased guidelines on appropriate complementary feed- ing. ${ }^{2}$ To facilitate these efforts, we have developed an approach based on linear programming analysis that objectively formulates and evaluates sets of foodbased recommendations; and, when optimal combinations of local foods are unlikely to ensure a nutritionally adequate diet, it confirms the need for alternative intervention strategies to complement a foodbased strategy. ${ }^{3}$

The approach itself uses mathematical optimization to select an optimal food basket (diet) from among all

Table 1: Key nutrition program planning and advocacy decisions addressed in each Module of the linear programming approach

Module I - formulating a food-based approach

1. What is the optimal set of food-based recommendations for a specific target population?

2. What combination of nutrient-dense foods will come as close as possible to achieving the desired nutrient levels?

3. What nutrients, if any, are likely to be low in local complementary feeding diets?

Module II - evaluating a food-based approach

1. Will a set of food-based recommendations ensure nutritionally adequate diets?

2. What is the lowest cost expected in diets conforming to a specific set of food-based recommendations?

3. What nutrients will likely remain low in diets adhering to the set of food-based recommendations being tested?

Module III - identifying appropriate nutrient dense local foods

1. What is the best combination of local foods to fill a nutrient gap?

2. To create a recipe to improve dietary adequacy, which foods should be selected?

Module IV - choosing one food-based approach from among alternatives

1. What are the comparative cost and nutritional benefits of alternative sets of food-based recommendations?

2. What is the impact on worst-case scenario nutrient levels and minimal cost of one specific recommendation in a set of food-based recommendations, i.e., is it worthwhile including it? 
Table 2: Data required to define linear programming parameters in the Modules I, II, III and IV analyses

\begin{tabular}{|c|c|}
\hline Data requirements & Modules \\
\hline A list of foods the target population typically consumes & All Modules \\
\hline $\begin{array}{l}\text { For each food, its nutrient content per } 100 \text { grams, a realistic portion size } \\
\text { per eating occasion, a maximum frequency of consumption per week, } \\
\text { and its cost per edible } 100 \text { grams (optional) }\end{array}$ & All Modules \\
\hline $\begin{array}{l}\text { The food consumption patterns }{ }^{\mathrm{a}} \text { of the target population } \\
\text { (low, average or high level) }\end{array}$ & Modules I, II, IV \\
\hline $\begin{array}{l}\text { The highest price the target population would be willing spend on their } \\
\text { infant's diet (optional) }\end{array}$ & All Modules \\
\hline The target population's breastfeeding status (breastfed - yes/no) & Modules I, II, IV \\
\hline The estimated average energy requirements of the target population & All Modules \\
\hline $\begin{array}{l}\text { The desired nutrient content of the target population's diet } \\
\text { (e.g., FAO/WHO nutrient requirements) }\end{array}$ & Modules I, II, IV \\
\hline
\end{tabular}

possible food baskets (diets) while simultaneously taking into account constraints that define the diet's energy content, cultural food consumption patterns, food acceptability, affordability, and the maximum quantities consumed. It includes four distinct modules, which can be used independently or sequentially depending on the decisions required. The decisions pertinent to each of its four modules are summarized in Table 1. To date, the linear programming approach has been successfully used to formulate or compare alternative sets of food-based recommendations for young Indonesian and New Zealand children (unpublished data). In this review, we have highlighted its value for designing and evaluating food-based complementary feeding recommendations. However, its use is not restricted to infants and young children. It can be used to formulate and evaluate food-based recommendations for any age group in any country.

In all contexts, linear programming has advantages over traditional trial and error approaches in terms of time, objectivity and the strength of evidence upon which to base decisions. $3,4,5,6$ The technical details of the approach have been described in detail elsewhere. ${ }^{3}$ Our intent in this review is to describe, in simple terms, the unique contribution it can make to the decision-making process involved in nutrition intervention program planning and advocacy for improved complementary feeding diets. The data requirements of the approach and the information obtained from each of the four modules are described in detail, below, using a series of hypothetical examples.

\section{Data requirements}

To create the mathematical models used in the linear programming approach, detailed dietary and food cost data are required (see Table 2), including a list of foods consumed by the target population and, for each food, a typical portion size per eating occasion, its maximum frequency of consumption per week, and its cost per edible 100 grams (optional). In addition, information about the food consumption patterns of the tar- get population and the maximum financial expenditure they are willing to spend on food (optional) are required as well as the desired energy and nutrient intake levels for the target population (e.g., FAO/WHO Nutrient Requirements ${ }^{7,8,9}$ ) and, for breastfed infants, the quantity of breast milk consumed. ${ }^{1}$

\section{Module I: Formulation of a set of food-based recommendations}

A user would select Module I if they intended to

(1) formulate a set of draft foodbased recommendations;

(2) examine the nutrient or food content of the diet that best achieves the desired nutrient levels 8,9 (i.e., the optimal nutrient contents); or

(3) identify nutrients that are below their recommendation levels, $, 8,9$ even in a diet that best achieves the desired nutrient levels.

The hypothetical example presented in Table 3, shows the results of a Module I analysis; namely, the nutrient content of the optimized diet expressed as a percentage of 
the desired levels, ${ }^{8,9}$ the foods selected in the diet and the consumption patterns of these foods (e.g., the number of average-sized servings of cereals, fruits, and vegetables in the diet). The food consumption patterns are used to define a draft set of food-based recommendations to evaluate and refine in Module II.

As shown in Table 3, the draft recommendations derived from this hypothetical Module I analysis were to consume grains 3 times a day, flesh foods $\geq 2$ times a week, legumes $\geq 4$ times a week, fruits $\geq 7$ times a week, and vegetables $\geq 7$ times a week. They characterize the diet that best achieves the desired nutrient levels without deviating to a great extent from the target population's average food consumption patterns. As such they are likely to be realistic for the target population, making them relatively easy to promote.

The results from this hypothetical analysis also show that iron and zinc are likely to be low in diets based on local foods, because their optimal levels were well below their desired levels (i.e., optimal amounts of $40 \%$ and $55 \%$ of desired levels, respectively; Table 3). For other nutrients, their optimal levels exceeded $80 \%$ of desired levels (Table 3), indicating that carefully selected combinations of local foods are likely to provide these nutrients in adequate amounts. In contrast, the results for iron and zinc indicate that alternative intervention strategies (e.g., fortification, supplementation) may be required to ensure their dietary adequacy; a possibility which can be confirmed in the Module II analysis.

Module II analysis: Evaluation of recommendations for a foodbased approach

A user would select Module II if they would like to

(1) test a set of food-based recommendations to determine whether local diets conforming to them are likely to be nutritionally adequate;
(2) explore the cost implications of a given set of food-based recommendations; and

(3) determine whether a foodbased approach alone is likely to ensure a target population's nutrient requirements are met.

The Module II analyses will indicate whether modifications to a set of food-based recommendations are required to improve them, and whether alternative intervention strategies are likely to be needed to eliminate nutrient deficiencies. The set of food-based recommendations tested in the Module II analyses can be those generated from the Module I analysis or a user-defined set of recommendations. The results are expressed as "worst-case" and "best-case" scenario nutrient levels, which indicate, for each nutrient, the lowest or highest level that is likely to occur in a diet that respects the set of food-based recommendations being tested. This informs the user whether a set of food-based recommendations will ensure that a diet based on them will be nutritionally adequate (i.e., worst-case

Table 3: The results of a Module I analysis showing the optimal nutrient content, ${ }^{a}$ the specific foods selected, and the selected food patterns ${ }^{\mathrm{b}}$ in the optimized 7-day Module I diet

\begin{tabular}{|c|c|c|c|c|c|}
\hline \multicolumn{2}{|c|}{$\begin{array}{l}\text { Optimal nutrient levels } \\
\qquad \% \text { Recommendation }\end{array}$} & \multicolumn{2}{|c|}{$\begin{array}{ll}\text { Foods selected } & \\
& \text { Serves/week }\end{array}$} & \multicolumn{2}{|c|}{$\begin{array}{l}\text { Food patterns } \quad \text { Serves/week } \\
\end{array}$} \\
\hline Protein & 134 & Rice & 14 & Grains & 21 \\
\hline Calcium & 80 & Rice porridge & 7 & Animal source foods & 2 \\
\hline Iron & 40 & Soy product & 4 & Legumes & 4 \\
\hline Zinc & 55 & Liver & 2 & Fruits & 7 \\
\hline Vitamin A & 192 & Spinach & 3 & Vegetables & 7 \\
\hline Vitamin C & 105 & Carrots & 4 & & \\
\hline Vitamin $B_{12}$ & 105 & Papaya & 5 & & \\
\hline Vitamin $\mathrm{B}_{6}$ & 98 & Banana & 2 & & \\
\hline Folate & 107 & Coconut & 3 & & \\
\hline Thiamine & 126 & & & & \\
\hline Riboflavin & 193 & & & & \\
\hline Niacin & 87 & & & & \\
\hline
\end{tabular}


Table 4: The results of a Module II analysis showing the worst- and best-case scenario results for the set of food-based recommendations tested, expressed as a percentage of desired amounts 8,9

\begin{tabular}{|l|c|c|}
\hline & $\begin{array}{c}\text { Worst-case scenario } \\
\text { \% desired amount }\end{array}$ & $\begin{array}{c}\text { Best-case scenario } \\
\text { \% desired amount }\end{array}$ \\
Protein & 133 & 165 \\
Calcium & 89 & 145 \\
Iron & 7 & 45 \\
Zinc & 35 & 101 \\
Vitamin A & 90 & 213 \\
Vitamin C & 122 & 255 \\
Vitamin $\mathrm{B}_{12}$ & 136 & 344 \\
Vitamin $\mathrm{B}_{6}$ & 91 & 157 \\
Folate & 121 & 224 \\
Thiamine & 61 & 189 \\
Riboflavin & 87 & 112 \\
Niacin & 55 & 136 \\
\hline
\end{tabular}

scenario levels of each nutrient $\geq 70 \%$ of desired levels) and whether a nutritionally adequate diet is achievable using locally available foods (i.e., best-case scenario levels of each nutrient are $\geq 100 \%$ of desired levels).

Table 4 shows the results of a Module II analysis for a set of hypothetical food-based recommendations. These results indicate that this set of food-based recommendations will not ensure dietary iron, zinc, thiamine and niacin adequacy (i.e., worst-case scenario levels $<70 \%$ ); indicating that modifications are needed to improve them. Similarly, the results in Table 4 show that a food-based approach, alone, will not ensure adequate iron intake (i.e., best-case scenario level for iron of $45 \%$ ), indicating that alternative intervention strategies, such as iron fortification or iron supplementation, are likely to be required to eliminate iron deficiency in this population (i.e., the iron density of local food sources is insufficient to achieve the target population's iron requirements). Whenever possible, such results should be confirmed with biochemical nutrient status data.

\section{Module III: Identification of nutrient-dense local foods that provide key problem nutrients}

A user would select Module III if they would like to identify a combination of foods that, together, would provide specific amounts of selected nutrients. These nutrient-dense foods or their sub-foodgroups can then be incorporated into a set of food-based recommendations to improve them. Unlike Modules I and II, the food basket selected in Module III does not represent a full day's diet, e.g., its energy content is less than the target population's estimated average daily energy needs.

To illustrate, Table 5 shows the food basket selected to provide a given amount of iron, zinc, calcium, thiamine and niacin, and the percentage of each nutrient's desired level that is provided by the individual foods. These results show that chicken liver (or the sub-group 'offal'), anchovies (or the sub-group 'small fish with bones'), soy products (or the subgroup 'legumes') or fortified cereals are likely to improve the worst-case scenario nutrient levels of a set of food-based recommendations if one or more of these foods (or sub-food-groups) are incorporated into them. It also indicates that one or more of these foods could be included in a recipe specifically created to improve complementary feeding practices.

\section{Module IV: Selection of a food-based approach from among alternatives}

A user would select Module IV if they would like to compare alternatives sets of food-based recommenda-

Table 5: The results of a Module III analysis showing the combination of nutrient-dense foods that best provide the selected nutrient levels and the proportional nutrient amounts each food provides

\begin{tabular}{|l|c|c|c|c|c|c|}
\hline & Number of servings & $\begin{array}{c}\text { Iron } \\
\%\end{array}$ & $\begin{array}{c}\text { Zinc } \\
\%\end{array}$ & $\begin{array}{c}\text { Calcium } \\
\%\end{array}$ & $\begin{array}{c}\text { Thiamine } \\
\%\end{array}$ & $\begin{array}{c}\text { Niacin } \\
\%\end{array}$ \\
Chicken liver & 2 & 8 & 10 & 0 & 22 & 34 \\
Anchovies & 2 & 7 & 10 & 40 & 10 & 15 \\
Soy product & 4 & 5 & 4 & 5 & 2 & 10 \\
Fortified cereal & 7 & 80 & 76 & 55 & 66 & 41 \\
\hline
\end{tabular}




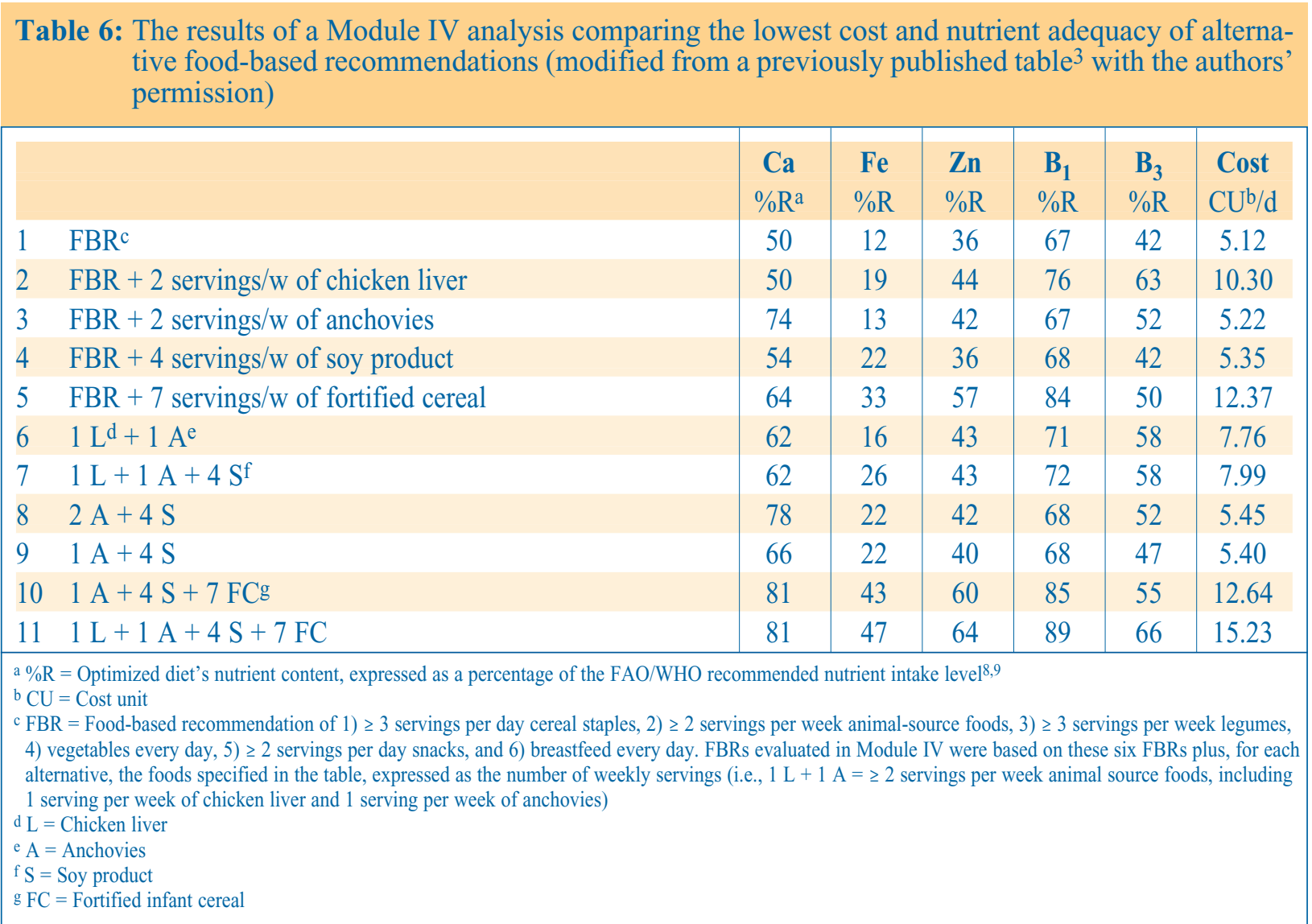

tions in terms of their worst-case scenario nutrient levels or lowest cost. As such, the results from this analysis provide objective evidence with which to inform the selection of a final set of foodbased recommendations from among alternative sets.

The Module IV analyses uses a sub-set of the Module II models, i.e., the worst-case scenario models for the key problem nutrients and cost (optional). Table 6 shows the comparative results of a hypothetical Module IV analysis, in which 11 alternative sets of foodbased recommendations that include or exclude different amounts of the nutrient-dense foods selected in Module III (i.e., chicken liver, anchovies, soy products or a fortified cereal) are compared. These results show that a recommendation to consume a fortified cereal daily or chicken liver twice a week will improve the worst-case scenario nutrient levels for all nutrients analyzed; however, they will have a marked impact on diet cost. Further, after examining combinations of specific recommendations, if diet cost is a key deciding factor, alternatives 7,8 or 11 (Table 6) may be selected over alternative 11, which has the highest worst-case scenario nutrient levels. Any number of sets of food-based recommendations can be quickly compared in a Module IV analysis to guide the final choice.

\section{Conclusion}

This review has demonstrated the way in which an approach based on linear programming analysis can rapidly and objectively inform food-based intervention program planning decisions and identify the need for alternative intervention strategies to complement them. Currently, advanced computer and linear programming skills are required to use the approach, which limits its widespread application. The development of userfriendly software would therefore greatly facilitate its use, providing a powerful tool with which to help public health professionals formulate or evaluate proposed sets of food-based recommendations. Once a user-friendly interface is developed, we believe its use will make an important contribution to international efforts to improve complementary feeding practices among young children.

\section{Reference}

1. Dewey KG, Brown KH. Update on technical issues concerning complementary feeding of young children in developing countries and implications for intervention programs. Food Nutr Bull 2003; 24: 5-28.

2. WHO/UNICEF. Global strategy for infant and young child feeding. Geneva 2003. Available at: http://whqlibdoc.who.int/publications/ 2003/9241562218.pdf.

3. Ferguson E.L., Darmon N, Fahmida U, Fritiyani S, Harper TB, Premach- 
andra I. Design of optimal food-based complementary feeding recommendations and identification of key "problem nutrients" using goal programming.. J Nutr. 2006;136: 2399-404.

4. Ferguson EL, Darmon N, Briend A, Premachandra I. Food-based dietary guidelines can be developed and tested using linear programming analysis. J Nutr. 2004;134:951-7.

5. Briend A, Darmon N, Ferguson E,
Linear programming: a mathematical tool for analyzing and optimizing children's diets during the complementary feeding period. J Pediatr Gastroenterol Nutr. 2003;36:12-22.

6. Briend A. Trial and error methods, "expert" guessing or linear programming? SCN News \#27, 2003. 36-39. Internet: http://www.unsystem.org/ scn/Publications/SCNNews/ scnnews29.pdf
7. FAO/WHO. Human energy requirements. 2004. Internet: ftp://ftp. fao.org/ docrep/fao/007/y5686e/y5686e00.pdf.

8. FAO/WHO. Protein and amino acid requirements in human nutrition. 2002. Internet: http://whqlibdoc.who.int/ trs/WHO_TRS_935_eng.pdf.

9. FAO/WHO. Human vitamin and mineral requirements. 2004. Internet: ftp://ftp.fao.org/es/esn/nutrition/Vitrin i/vitrni.html.

Editor's note: A comprehensive tool 'NutriSurvey' for linear programming developed by Juergen Erhardt, SEAMEO-TROPMED, Jakarta can be downloaded from the internet (http://www.nutrisurvey.net/lp/lp.htm). Dr Erhardt describes the use of NutriSurvey in the box.

\section{Linear Programming with NutriSurvey}

Linear programming is a technique for optimizing an outcome in a given mathematical model, given a list of requirements that are represented as linear equations. Nutrition can also benefit from this technique. Currently, however, there are not many possibilities for optimizing diets with linear programming.

While this function is integrated in and can be performed using Microsoft Excel, it is not easy to use and all data (e.g. nutrient values, recommendations) have to be entered into a spreadsheet. An easier way to do this is provided on the website, NutriSurvey (www.nutrisurvey.net), which has a special application for linear programming (www.nutrisurvey. net/lp/lp.htm).

With this application, it is possible to optimize a diet with the least expensive components (Screenshot 1). Since the food data and nutrient recommendations are already integrated into the model, it is much easier to use than the linear programming function of Excel.

Additionally, it has a user-friendly interface, into which all data can be entered (Screenshot 2). Nevertheless, since food data always has some amount of variation and the nutrient content of some foods may not match identi- cal with the bioavailability data of the model, the calculated food records may need additional interpretation or modification.

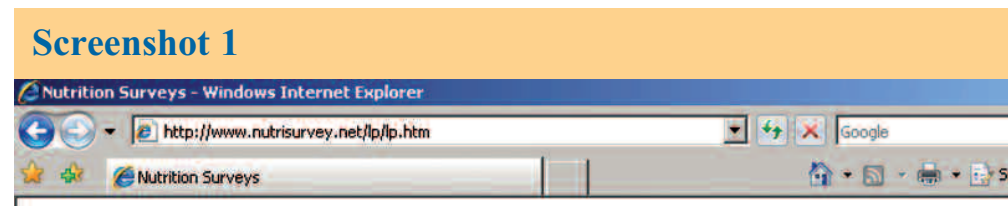

Linear Programming Module of NutriSurvey

Linear programming is a mathematical tool which can give clear answers to very practical questions faced in the nutritionists working in developing countries:

- Is it possible with locally available food to provide all nutrients needed by a young child ?

- What quantity of nutrient rich foods are needed to provide all micronutrients ?

- If this is possible, how much will it cost ?

- What food combination is best adapted to provide all needed nutrients at the lowest cost ?

- Are micronutrient supplements or fortified foods useful to feed a child a balanced diet at low cost ?

Linear programming is based on the examination of multiple inequalities a the same time. The mathematical prin method and its applications to human nutrition have been described elsewhere (see links at the end of this page)

The Linear Programming Module of NutriSurvey is a user-friendly software which allows this type of analysis.

To install the software, please download the following file lp. zip and unzip it in an empty directory. You can star by clicking in the chosen directory on the fle 'nutrisurvey. exe'. You get the following screen:

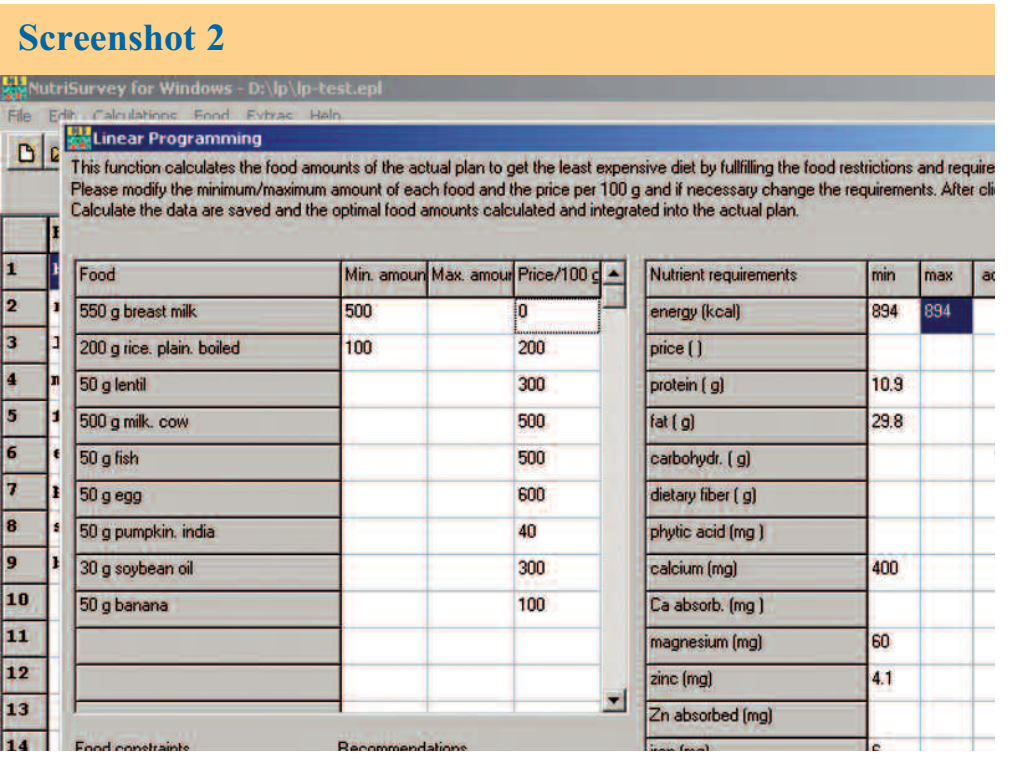

